\title{
LOS LUGARES DE LA MEMORIA EN BUENOS AIRES. MANSIÓN SERÉ A DIEZ AÑOS DE SU RECUPERACIÓN.
}

\author{
Silvina Fabri*
}

\section{Resumo}

El presente artículo se propone reflexionar a partir de algunas categorías que abrevan en el campo de los estudios geográficos; como son lugar, usos del espacio urbano y emplazamiento territorial, el significado de un lugar de memoria y los cambios que en él se fueron operando a partir de prácticas sociales y políticas en relación con la recuperación de un ex - centro clandestino de detención: La Mansión Seré, donde hoy funciona La Casa de Memoria y la Vida ubicada en el Municipio de Morón, Provincia de Buenos Aires.

Palabras Clave: lugar de memoria- política pública- usos del espacio urbano - construcción de la memoria colectiva.

\begin{abstract}
Does present article propose to think from some categories that water in the field of the geographical studies since they are place, uses of the urban space and territorial emplacement the meaning of a place of memory and the changes that in him were occurring from social and political practices in relation with the recovery of one ex--clandestine center of detention: The Mansion Seré, where today there works The House of Memory and the Life located in the Morón district, in the Province of Buenos Aires.
\end{abstract}

Key words: place of memory - public politics - uses of the urban space - construction of the collective memory

\section{Introducción}

"No hay razón para erigir un culto a la memoria por la memoria;

Sacralizar la memoria es otro modo de hacerla estéril.

Una vez restablecido el pasado, la pregunta debe ser:¿para qué puede servir; ¿Y con qué fin? Tzvetan Todorov
Con el presente trabajo ${ }^{1}$ nos proponemos avanzar en el proceso de reconstrucción y transformación de un ex Centro Clandestino de Detención de la última dictadura argentina en un lugar de memoria y, puntuar en consecuencia, los cambios en los usos del espacio que se han operado modificando la significación del sitio en sí mismo y en relación al sistema intraurbano (paisaje urbano) ${ }^{2}$.

Para la geografía urbana, la ciudad es

- Licenciada en Geografía. Docente del Departamento de Geografía e Investigadora del Proyecto UBACyT F110 Lugares y políticas de memoria .Acontecimientos, sujetos e instituciones (1955-2007), dirigido por Cora Escolar, Instituto de Geografía, Facultad de Filosofía y Letras, UBA. 
entendida como un producto social y singular que se manifiesta en el emplazamiento y la función de los espacios que la constituyen, de allí que se tipifiquen los usos del espacio en relación a estos patrones. La clasificación permite analizar el espacio urbano desde una doble perspectiva. En primer lugar, una morfológica y tipológica en donde prima la forma de los espacios (Morfología Urbana); en segundo lugar, una orientación funcional en donde prima la dimensión histórica de los usos del espacio ${ }^{3}$ y el cambio que en él van operando las prácticas sociales en relación al espacio vivido. (Ortega Varcárcel; 2000: 401-406). Por otra parte, a partir de la necesidad de no caer en el causalismo espacial y morfológico que propulsó la geografía urbana desde los años cincuenta y sesenta, Werlen sostiene que "el espacio [como] concepto teórico central de la geografía social, opera en el ordenamiento espacial de los objetos y se convierte en relevante como una condición necesaria y como consecuencia de la acción humana más que como causa. Las acciones tienen orientaciones específicas, de acuerdo a los objetivos que las guían, en relación con objetos localizables. Los objetos localizables, por sí mismos, no causan actos, aunque por supuesto los enmarcan" (1988: 4). Lo interesante de este planteo nos lleva a la idea de que la construcción del espacio urbano se sustenta a partir de la efectivización de prácticas sociales, por ello, "el estudio de la geografía urbana no concluye con el análisis estático de sus componentes, sino que es preciso añadir la perspectiva dinámica; es decir, las necesidades cambiantes de la sociedad que se traducen en todos o en algún componente del paisaje o en sus contenidos (usos del suelo)" (Estébanez, 1988: 260). Se debe incorporar también el estudio de las formas en que los grupos sociales o los individuos perciben el paisaje urbano, describir e interpretar cómo los componentes objetivos de éste se configuran dando como resultado una imagen representativa y cargada simbólicamente en la valoración que realizan los sujetos para configurar su sentido de pertenencia y de identidad (Carter; 1983:32). Como señala Portillo "la vida urbana en sí, tanto en lo referido a las actividades productivas como en lo concerniente a la cotidianeidad (...), connota múltiples y expansivos usos sociales - no individuales - del espacio; esta circunstancia de hecho, va a estar permanentemente enfrentada a la apropiación privada (...) de las relaciones sociales" (1991: 21)

Siguiendo a de Certau (1974:265) las formas que establecen cómo se fabrica una ciudad (es decir la materialidad de las políticas de intervención urbanística), sus códigos y sus reglas de convivencia (los marcos legales o morales sobre las que se vigilan los comportamientos sociales) se encuentran enmarcadas en una red de relaciones infinitamente amplia y son ellas las que habilitan la forma en que los sujetos se relacionan con el espacio urbano y la apropiación que pueden establecer con el mismo.

La política pública ${ }^{4}$, en este caso municipal, propició el camino de recuperación del espacio imprimiendo una nueva marca en el lugar, desandando las huellas que supo dejar el pasado en pos de la construcción de nuevas narrativas acerca de la memoria, a través de la rearticulación de los usos del espacio y de la concreción de la participación de la comuna en diversas actividades tendientes a reforzar el sentido de la construcción de memoria colectiva.

El sitio, al que hacemos referencia, cobra entonces, una nueva identidad. Los lugares de memoria, siguiendo a Nora (1998) podrían entenderse como los sitios que condensan significaciones en torno a una política nacional de la memoria, por ello son entendidos como productos sociales (con contenidos culturales y políticos específicos) donde la memoria se materializa otorgando cierta especificidad al lugar. Las nueva relaciones de los sujetos con el espacio urbano producidas por el cambio en el uso urbano del lugar a partir de la puesta en marcha de la política de memoria municipal modifica la fisonomía del espacio urbano entretejiéndose en un mismo proceso los cambios en la cotidianeidad y la reconstitución de ciertos símbolos urbanos (Harvey, 1992:340-354), que modifican las subjetividades de los sujetos que viven en ella (Shields; 1991:211-216). Para Williams (1980:226) estos cambios están definidos por las modificaciones de las estructuras del sentir. Son importantes los significados y valores tal como son vividos y sentidos activamente, puesto que las relaciones 
existentes entre ellos y las creencias sistemáticas o formales en la práctica varían. Estas últimas son las que le dan forma a la estructura de la experiencia.

Entendemos que la recuperación y la reconfiguración de los usos socio-espaciales de los Ex Centros Clandestinos de Detención, implican la efectivización de un proceso de lugarización, que lo diferencia y lo separa del resto de la trama urbana imprimiéndole una nueva significación. Es esta nueva marca la que implica el distingo, la que posibilita que los sujetos sociales puedan identificarse con él desde un nuevo posicionamiento, que puedan apropiarse de ese espacio y darle un nuevo sentido. Como bien especifica Agnew "el lugar es también más que un objeto. La práctica concreta y cotidiana da surgimiento a una mediación o estructura de sentimiento cultural (...) este sentido del lugar fortalece la definición socio-espacial del lugar, digamos, desde adentro. La identificación con el lugar que puede seguir, contribuye como otro aspecto del significado del lugar: un lugar o territorio puede convertirse en un objeto de identidad para un sujeto, en su diferenciación con otros lugares" (1993:13).

Puesto que el lugar ${ }^{5}$, como concepto, desde la perspectiva geográfica, muestra un matiz distintivo que habilita la pertinencia de pensarlo en su costado de constructo social, en su dimensión subjetiva, acerca de cómo ese espacio es vivido y apropiado, en su vínculo con la propia experiencia del sujeto tanto práctica y material como mental y simbólica, entendemos que estos son dos planos que no pueden disociarse entre sí si se pretende entender la complejidad de la construcción de estos enclaves territoriales ${ }^{6}$ en donde se construye una memoria.(Ortega Varcárcel, 2000: 527)

Por un lado, los avances en cuestiones referidas al conocimiento de las transformaciones materiales operadas en los diez años que lleva el proyecto de recuperación del centro clandestino de detención Mansión Seré, están puntuados a partir de la recopilación de información secundaria. Por otro lado, los desarrollos de las efectivas transformaciones en el ámbito simbólico e imaginario de la comuna en relación a la Casa de la Memoria y la Vida, en el Municipio de Morón, es un camino abierto que pretendemos abarcar en un trabajo futuro.
Por ende, el objetivo fundamental de este escrito es dar cuenta de un panorama contextual y de las actividades efectivas que se llevaron a cabo en el espacio recuperado, tratando de contribuir al desarrollo de ciertos conceptos que son ineludibles a la hora de trabajar con las Políticas Públicas de la Memoria.

Para Jelin (2002: 53-58) la concreción de las políticas que llevan a la lugarización de la memoria, implica una capacidad de decisión de los actores intervinientes en dicho proceso. Siguiendo estos lineamientos, nos preguntamos entonces ¿cuáles son los objetos materiales o los lugares ligados con los acontecimientos del pasado susceptibles de ser seleccionados para tales fines? La decisión de habilitar espacios para la memoria, la denuncia de crímenes de lesa humanidad, y el homenaje a las víctimas del terrorismo de Estado podría pensarse como el resultado de un proceso intrincado y una trama compleja de luchas y conflictos entre quienes propician la concreción del proyecto y quienes la rechazan, entre el contenido de la memoria individual y la narrativa de lo que se construye como memoria colectiva.

\section{La Mansión Seré en el foco de la política pública Municipal, Ciudad de Morón, Buenos Aires}

El recorrido cronológico ${ }^{7}$ de la Mansión Seré hacia "Casa de la Memoria y la Vida"8 puede pensarse como una sucesión fotográfica de los momentos históricos de la argentina. En un primer momento, Jean Sère, un terrateniente vasco francés, a mediados del siglo XIX adquirió 60 hectáreas en Morón, oeste de la Provincia de Buenos Aires, obtención lograda a partir de las rentas resultantes de la actividad ganadera. Allí, una de sus hijas (Leocadia Sère) edificó una mansión en el 1900, utilizada como casco de estancia. Los coletazos de la crisis de 1930 dieron origen, mediante loteos masivos, a lo que se conoce actualmente como Barrio Seré.

La parte donde se ubicaba la mansión (un palacete de estilo francés de dos plantas) fue comprada por el Instituto de previsión social de la capital Federal, en 1949. Luego, de estar abandonada, la dictadura de Juan Carlos Onganía 
cedió el caserón a la VII Brigada Aérea de Morón, para ser habilitado como Casino de Oficiales. Luego del golpe de Estado de 1976, Osvaldo Andrés Cacciatore, por entonces intendente de facto de la Capital Federal, otorgó su uso a la Fuerza Aérea, donde se instaló el Centro Clandestino de Detención conocido como Mansión Seré o Atila $^{9}$ en la jerga militar. En el entonces partido de Morón, se denunciaron 250 desapariciones de personas y se identificaron otros ocho lugares de tortura y detención clandestina, entre los que figuran comisarías, dependencias militares y casas particulares o tomadas. El cierre de la Mansión Seré fue precipitada luego de la fuga de cuatro detenidos desaparecidos ${ }^{10}$. Luego de este episodio, la mansión fue primero incendiada y luego dinamitada por los represores con el fin de borrar las huellas de su accionar.

Con el advenimiento de la democracia en el año 1983, la Municipalidad de la Ciudad de Buenos Aires cedió el terreno al Municipio de Morón, el gobierno municipal con autorización de la Municipalidad de la Ciudad de Buenos Aires, transformó el predio, en 1985, bajo la intendencia de Néstor García Silva en un polideportivo y sobre los cimientos de la mansión se creó una cancha de fútbol. ${ }^{11}$

Ya en la década del '90, Juan Carlos Rousselot ${ }^{12}$ asume como intendente del Municipio, quien manda a construir una réplica de la casona original para sus futuras reuniones de gabinete sin autorización del consejo deliberante de la época. Por entonces, el predio de Castelar permanecía cerrado a los vecinos. Finalmente, tras innumerables denuncias de corrupción el intendente no pudo utilizar la "olivos de Morón" o la "Casa Blanca" como era conocida la mansión por aquellos días.

La tarea de convertir la Casa Blanca en Casa de la Memoria y la Vida y sede de la Dirección de Derechos Humanos del Municipio de Morón fue propuesta el año 2000,a través de la gestión del intendente Martín Sabatella y un grupo de personas provenientes de diversas áreas tanto educativas, judiciales, de Organismos de Derechos Humanos y vecinos ${ }^{13}$. El entonces intendente, convocó a una reunión en el salón Mariano Moreno de la Municipalidad en donde participaron y discutieron alrededor de 30 personas acerca de los pasos a seguir con respecto al predio. La idea principal que surge de esta reunión fue la necesidad de recuperar el sitio para construir un espacio destinado a la reflexión acerca de la memoria abierto a los vecinos.

La concreción de la recuperación del predio que supo ocupar el ex centro clandestino Atila se potencia con el nacimiento del Proyecto Mansión Seré, integrante del Programa de recuperación de espacios vinculados al Terrorismo de Estado. El 1 de julio de 2007, el predio pasó definitivamente al Municipio de Morón "con la responsabilidad indelegable de la reconstrucción del pasado, presente y futuro, para ejercitar la memoria y construir vida donde hubo muerte" (Sabatella Martín, discurso inaugural de la Casa de la Memoria y la Vida) donde quedó oficialmente inaugurado como Lugar de Memoria.

Hoy funciona como un espacio público destinado a actividades sociales, culturales, artísticas, recreativas y deportivas, donde además se llevan a acabo tareas arqueológicas y antropológicas en los cimientos de la antigua mansión.

Diferentes sectores participaron de las obras de recuperación y resignificación del espacio con "el propósito de contribuir en la búsqueda de la verdad y la justicia, promover la memoria colectiva sobre la historia reciente y generar un espacio de participación y diálogo en torno a los derechos humanos. Está abierta a la comunidad y a organizaciones de la comunidad." (El Diario de Morón, junio 2010)

Podemos precisar, en este sentido, que el debate sobre el "uso" del espacio recuperado fue resultado de la acción municipal, ya que la política impartida por el Municipio tuvo un efecto verticalista en su dirección y efectivización de las políticas tendientes a producir prácticas de marcación territorial delineando un nuevo sentido a las viejas marcas urbanas que los mecanismos represivos de la dictadura militar dejaron como huella en el entramado urbano.

Si entendemos a las políticas públicas de memoria como prácticas de marcación territorial ${ }^{14}$ efectiva, es decir, como prácticas que hacen visible la denuncia acerca del antiguo uso del sitio; 
la posibilidad de delinear un nuevo sentido de aquellas estructuras funcionales a los mecanismos de represión de la última dictadura, abarca desde diferentes formas de homenaje y conmemoración como placas recordatorias, cambio de nombres a las calles y lugares de recreación, hasta los graffitis, murales y pintadas en las cercanías del ex CCD. Como sostiene Díaz "las formas y contenidos de las marcas [territoriales] de la memoria se van transformando conforme el paso del tiempo. (...) Las marcas de los últimos años, promueven el recuerdo de los desaparecidos apelando a la reconstrucción de su identidad. Las víctimas aparecen individualizadas, caracterizadas, recordadas desde sus lugares de pertenencia social. Además, las placas, murales, parques, calles y monumentos promueven el sentido de la memoria y operan como espacios de transmisión y reapropiación de los hechos relacionados con la última dictadura militar" (2002:39).

Estas marcas, tratan así de dar materialidad a la memoria y de hacerla pública, visible a las miradas y a su apropiación"15. "Las marcas son espacios físicos transformados "en un 'lugar' con significados particulares, cargado de sentidos y sentimientos para los sujetos que lo vivieron" Entraña en esta perspectiva la figura de que las marcas son territorios en tanto devienen lugares, esto es espacios apropiados por la vía de alguna construcción de sentido. Sin embargo, creemos que la dimensión territorial no implica una mera lugarización sino que trae la carga simbólica del límite impuesto y establecido por la política". (Besse; 2005:19)

Al mismo tiempo, estos lugares de memoria pueden entenderse, como prácticas de construcción de memoria social urbana, es por ello que trascienden el sentido que se imparte desde las esferas del poder político a través de determinada política, en nuestro caso el Proyecto de La Casa de la Memoria y la Vida. De manera más específica "el apego al lugar se expresa en su significación a través del lenguaje de la vida cotidiana, a través de la fusión conceptual del contexto geográfico y la experiencia, y este lenguaje y su contenido simbólico son el fundamento de la constitución del lugar (...). La experiencia humana siempre está arraigada a un lugar" (Entrikin: 1988: 8)

Repensar la participación cultural, social y política de los agentes intervinientes en este nuevo nudo de lugar-memoria implica repreguntarse acerca del grado de participación vecinal, la representación de los procesos de recuperación del lugar en relación a las prácticas cotidianas de los vecinos, avanzar en la exploración de los impactos de estas políticas en las geografías de la vida cotidiana.

En esta reapropiación del lugar, se establece un nuevo vínculo estrecho entre cómo es vivido cotidianamente el sitio, esos lugares que se convierten, por la acción política, en lugares patrimoniales de memoria pues invisten al recorte espacial con un nuevo sentido (Besse:2005:20-22), se asientan sobre la base de la producción de sujetos que los piensa, los sienten y los usan a partir de un nuevo sentido de lugar, donde la rememoración activa nuevos procesos de subjetivación y de representaciones ante el proceso de recuperación.

Las discusiones que postulan la importancia y la incidencia que poseen las políticas de intervención y construcción de la memoria colectiva en el espacio urbano, (ya sean de carácter público como de carácter privado), nos sirven de referencia para intentar mostrar cómo dichas políticas apuntan a darle forma a un sentido de memoria, por lo que entendemos que dibujan, moldean y modifican la memoria colectiva en una sociedad, como así también sus prácticas cotidianas en torno a ella.

En este artículo, siguiendo a Huyssen (2002: 14-18), entendemos a la memoria como el espacio de construcción en el que los recuerdos se tornan colectivos y han traspasado el umbral de lo netamente individual y personal.

Este proceso de construcción social de la memoria se torna palpable a través de la generación de ciertas políticas que apelan a darle forma a la promoción de espacios de transmisión y recreación de la "memoria colectiva". Los espacios y monumentos con significación que conmemoran a personajes públicos o con fechas significativas no son estáticos, sino que se redefinen en tanto el valor del proceso evocado. $Y$ en alguna medida, estos espacios, al constituirse en monumentos 0 
museos, influyen en el sentido que se le otorga socialmente al proceso evocado (Bustigorry; 2005: 930) es lo que nos lleva a plantearnos la pregunta acerca de cuáles fueron efectivamente los alcances del funcionamiento y las actividades desarrolladas en la ex Mansión Seré. Actividades y prácticas que han servido para hacer marca y visibilizar el lugar.

La Mansión Seré ubicada en el actual "Gorki Grana", predio municipal donde hoy funcionan dos dependencias del Municipio de Morón: la Dirección de Derechos Humanos y la Dirección de Deportes, además de la actual Casa de la Memoria y La Vida, es el centro y núcleo de las políticas públicas municipales en torno a las cuestiones de memoria en la comunidad de Morón.

Allí se produjo una resignificación del sitio tanto en sus características físicas y materiales (tangibilidad - visibilidad), como así también de su uso (funcionalidad), al mismo tiempo que se modificó su sentido de ser (significación). Lo cual produce efectos en el ámbito barrial y en los sujetos participantes, al mismo tiempo que apertura un nuevo canal simbólico acerca de ese lugar en relación con la memoria que está siendo construida.

\section{La memoria como dispositivo: hacer ver... hacer pensar...hacer recordar.}

\begin{abstract}
"La memoria es un dilema: no se puede vivir faltando a la memoria Tanto como es imposible vivir subordinado, atado (...) a una memoria transparente y todopoderosa" Jack Fuchs (sobreviviente de Auschwitz)
\end{abstract}

Ante una supuesta pérdida de la memoria reciente en América Latina, producto de los "fantasmas del pasado", el trauma de la dictadura y la elaboración de ese trauma en el proceso postdictatorial (Achugar, 2003:194-195; Caletti, 1998: 18) podríamos establecer que la construcción de la/s memoria/s se encuentra íntimamente relacionada con el dueto memoria - olvido, esto es: imprescindibles negociaciones entre lo que se recuerda, entre los "olvidos elegidos" y los "olvidos impuestos". (Kaës, 1991:153-154; Caletti, 1998: 19; Todorov, 1995: 27-29 ), allí se imbrican ciertos poderes y ciertos valores que dan forma a la memoria colectiva, que de esta manera se torna "un elemento esencial de los que hoy se estila llamar la identidad individual o colectiva, cuya búsqueda es una de las actividades fundamentales de los individuos y de la sociedad de hoy (...) La memoria colectiva (...) no es sólo una conquista: es un instrumento y una mira de poder" (Le Goff: 1977:182)

Pensar en la historia reciente puede ser una manera de reflexionar problemáticamente la situación a la que se enfrenta el que narra... los dichos suelen estar plagados de memoria, la memoria siempre está plagada de olvidos, pero de estos se puede nutrir una nueva historia. En la construcción de estos nuevos relatos acerca de lo acontecido, el espacio público ha cobrado un papel fundamental en el momento de construir identificaciones y referencias acerca de la memoria a través de marcas territoriales que identifican los lugares con un sentido especificable.

En el espacio público, monumentos y otras marcas territoriales, así como el establecimiento de archivos y museos, son algunas de las manifestaciones conmemorativas que confluyen en la configuración (y reconfiguración) del recuerdo.

Simultáneamente, en la esfera cotidiana, el pasado también es reelaborado, se somete a debate a través del intercambio de relatos "que recuerdan" conformando un núcleo de producción de memoria social. Es en este sentido que la memoria a parece como dispositivo en el sentido foucoultiano del término ${ }^{16}$.

Los proyectos de recuperación de los CCD en tanto políticas orientadas a transmitir y a preservar la memoria de los acontecimientos sucedidos en la última dictadura militar, posibilitan la discusión sobre la utilización de estos espacios, que, en definitiva plantean la cuestión profunda acerca de el qué $\boldsymbol{y}$ el cómo resguardar y transmitir la memoria y la historia de los hechos ocurridos (Sonderéguer, 2000: 37-39). La pregunta entonces girará en torno a cómo se lee ese pasado reciente para poder construir un relato de los acontecimientos y al mismo tiempo en cuáles fueron las condiciones 
de posibilidad para que esto efectivamente sea posible. Para Sonderéguer (2000:37) los años ochenta definieron un pacto ideológico cultural que convirtió la demanda de justicia en demanda política, lo cual se convirtió en el legítimo sostén del orden democrático que se comenzó a construir. La memoria tejió su trama de legalidades y tabúes, concedió un repertorio de sentidos, autorizó unas voces, prohibió otras ${ }^{17}$. Se puso el acento en los testimonios de horror, tortura, las víctimas de los abusos y violencia, en la descripción minuciosa de la violación de los derechos humanos.

A fines de los años noventa nuevos discursos y posicionamientos hacen que los acontecimientos sean narrados de otra manera, la construcción del sentido de los hechos manifiesta nuevas opciones de valor, una reelaboración y cambios en los juicios y supuestos que articulan la memoria colectiva. Se da entonces una significación y una revalorización de los recuerdos del pasado reciente, lo cual expresa un giro en las estrategias político- ideológicas en relación a la memoria. Esta cronología y explicación dada por Sonderéguer (2000: 38) puede solaparse con la cronología que relatábamos al inicio del trabajo acerca de los avatares por los que el predio de la Mansión Seré pasó hasta constituirse y funcionar como casa de la Memoria y La vida.

Una vez emplazado el proyecto dentro de la trama barrial, el uso, vínculo y significación que produce (y reproduce) la materialización de la memoria en tanto prácticas de rememoración/ conmemoración (Jelin; 2002: 53-55) conllevan a una reestructuración de la vida cotidiana. El lugar ingresa en un nuevo mapa mental ${ }^{18}$ de la comunidad siendo origen y destino para múltiples propósitos y nuevos sentidos. Proceso que puede llevarse a cabo mediante la inscripción de este sitio en el plano de lo público, es decir, abierto, distribuido, accesible (en oposición a lo clausurado y oculto de lo privado). Como señalan Escolar y Palacios este sitio puede pensarse como "un lugar público no sólo porque pertenece a la órbita de lo estatal (o municipal) sino porque además, a través de este Espacio, se ha vuelto visible aquello que estaba oculto, privado de visibilidad". (2010: 8),

Según el discurso municipal, el cambio en el uso del espacio no fue meramente cosmético sino que se trató de expresar distintos conceptos que siempre fueron centrales para la gestión municipal: lo vital de conocer el pasado reciente, la necesidad de saber el destino de los desaparecidos, y la obligación que el país tiene hacia sí mismo de que finalmente haya juicio y castigo a los culpables de tantos secuestros y asesinatos durante la dictadura militar ${ }^{19}$ La legitimación de este discurso, viene asegurada por el contexto de producción y el énfasis que puso el gobierno del intendente Martín Sabatella en la necesidad de recuperar dicho espacio, pero también muestra las pautas y lineamientos con los que el municipio trabajó en la construcción de este sitio de memoria. La tarea de desentrañar las aristas más sobresalientes del Proyecto en cuestión nos lleva al siguiente punto.

\section{Excavar en la memoria: Para que la historia no sea sepultada}

Si la inauguración de la sede de Derechos Humanos fue toda una definición del gobierno municipal acerca de su visión del terrorismo de estado, lo fue también el Proyecto ArqueológicoAntropológico Mansión seré, mediante el cual el Municipio y la Facultad de Filosofía y Letras de la Universidad de Buenos Aires iniciaron las tareas de recuperación de la vieja mansión incendiada y demolida que había sido el CCD Atila.

Este proyecto se inscribe como una iniciativa precursora en el país, en relación a la recuperación de espacios destinados a incentivar la memoria colectiva. A través del rescate del patrimonio tangible e intangible, la conservación de la estructura y la historia del sitio a partir de la recopilación de testimonios de diversos actores sociales y la preservación de la memoria histórica sobre los usos del lugar antes, durante y después de su utilización como centro clandestino de detención.

Las excavaciones de las estructuras subterráneas (sótano y pozo de agua, por ejemplo) están abiertas a la visita de la comunidad y fueron también los primeros pasos para encontrar pruebas judiciales y evidencias que sirvieran de base de investigaciones judiciales ${ }^{20}$. El equipo interdisciplinario (más de treinta investigadores) encargado de estas tareas (arqueólogos, antropólogos, arquitectos, 
paisajistas, sociólogos e historiadores) contó con los aportes de la comunidad a través de talleres con vecinos y testigos que hicieron aportes desde el relato de sus recuerdos hasta el aporte de elementos pertenecientes a la Mansión de cuando estuvo abandonada como maderas, mármoles, (periodo 1945-1966) y fotografías del lugar. "Toda la información que recabamos se contrasta con lo que cuentan los detenidos. Todo el material que sacamos es fichado, se analiza y se guarda pues también es brindado como prueba en el juicio por el que se condenó a los brigadieres de las bases de Morón y Palomar" (Paciente, Mariano, investigador que se desempeña en el área de archivo del proyecto)

Como resultado de este programa, los trabajos de excavación iniciados el año 2002 posibilitaron la recuperación de gran cantidad de objetos y dejaron al descubierto la totalidad del perímetro y divisiones internas de la parte principal de la Mansión Seré.

En el año 2006, se produjo un cambio en la configuración organizativa del proyecto, lo que llevó a que la administración del lugar fuera enteramente municipal y se solventara con fondos del mismo. En este segundo periodo se realizaron obras de techado para preservar las estructuras y se comenzaron a organizar visitas guiadas orientadas a los visitantes en general ${ }^{21}$.

Los ejes principales sobre los que se asienta este proyectos pueden resumirse en:

El recate de toda evidencia material (objetos y estructuras) como parte de la reestructuración histórica del lugar en relación con los testimonios orales, documentos escritos y visuales. "Teniendo en cuenta que la evidencia se percibe como "marca" o señal de reconocimiento para las personas que pasaron por este lugar, y por consiguiente como la posibilidad de convertirse en evidencia judicial. 2) La recuperación de espacios y objetos asociados que permiten darle materialidad a esa historia sepultada, pero no silenciada. Recuperación de los lugares que posibilitan la discusión y reflexión acerca de nuestra historia reciente ${ }^{22}$.

La historia del lugar como así también el quiebre de la vida cotidiana relacionada con la represión llevada adelante por el terrorismo de Estado se intenta reconstruir a partir del trabajo arqueológico por un lado, y la reconstrucción de historias de vida de los actores participantes, por otro. Esta tarea se enmarca así en un trabajo del equipo de investigación interdisciplinario que tiene sede en la ex Mansión Seré.

La metodología de trabajo nos resulta interesante a la hora de tratar de reconstruir algunos lazos en la construcción de la memoria, que generalmente está sesgada por las elecciones que se realizan al "tratar de develar los procedimientos por los cuales los sujetos puntúan su experiencia" Escolar (2009:2). La elaboración que surge de la intervención en ese recorte de lo real es una construcción de la memoria social y por lo tanto está posicionada política, histórica y culturalmente.

\section{En la recuperación: tareas y actividades en marcha en la Casa de La Memoria y La vida.}

Los usos del espacio recuperado en la Mansión Seré marcan de alguna manera el impacto que han tenido las diversas actividades realizadas desde allí abiertas a la comunidad de Morón, desde su creación más de 15000 estudiantes de diferentes instituciones y distritos participaron de los talleres educativos que dicta la Dirección de Derechos Humanos con Sede en la Casa de la Memoria y la Vida. Dichas actividades estuvieron destinadas a todos los niveles educativos, desde preescolar a terciario y universitario.

Al mismo tiempo se conformó el programa "Jóvenes y Memoria", en el cual participan estudiantes del distrito investigando y presentando trabajos en torno al eje "Autoritarismo y Democracia", como resultado del convenio existente entre el Municipio y la Comisión Provincial por la Memoria ${ }^{23}$. La propuesta de este programa consiste en el abordaje de la historia reciente en la escuela a partir de la premisa fundamental de que sean los estudiantes los que se apropien significativamente de las experiencias pasadas ${ }^{24}$. En palabras de Raggio (2006: 2) el programa plantea dos desafíos: uno pedagógico, que refiere a innovar la enseñanza de las ciencias sociales y de la historia en particular; y otro político: sumar a las nuevas generaciones en el proceso de elaboración del pasado común y por tanto a la construcción de ciudadanía identidades colectivas. Lejos de ocluirse, 
el carácter controversial, conflictivo e inacabado del proceso de elaboración del pasado -que se expresa en los "agujeros negros", en los silencios, en las diferentes versiones e interpretaciones sobre los hechospotencia las motivaciones de los alumnos, produce una genuina curiosidad por conocer y comprender, y los incorpora como un actor más dentro del proceso de elaboración del pasado; pues ellos, finalmente, construirán un relato que, aun tramado con palabras o silencios de otros, será dicho con voz propia.

Por otro lado, la dimensión micro histórica; que toma elementos de la vida cotidiana de los jóvenes, para propiciar las investigaciones les permite trabajar con una mirada menos opaca, menos abstracta y a la vez menos esquemática y estereotipada que la que logran aprender en los textos escolares y otras narraciones disponibles.

Para Raggio "la experiencia a la que abre paso el programa provoca un trabajo sobre la subjetividad de los participantes, e impacta tanto en las formas de percibir el presente -en tanto lo inscribe en una continuidad temporal más densa, ensanchando los márgenes de la vivencia personal como en los modos de pensarse y actuar individual y colectivamente. Resulta difícil evaluar estos aspectos y la profundidad del impacto; no obstante, tanto en las investigaciones como en los relatos sobre la experiencia realizados por alumnos, alumnas y docentes, estas cuestiones se expresan una y otra vez. La experiencia los excede, ya que tanto la institución escolar como la comunidad se ven interpeladas, en una doble dimensión, como territorios de memoria y como actores históricos" (2006:2). Las preguntas de los jóvenes provocan un trabajo colectivo sobre la memoria, expresado en la creación de espacios de habla y escucha antes obliterados, a la vez que inscriben la historia local en la historia nacional y genera nuevas conexiones de sentido operando en el plano de lo simbólico que conlleva construir memoria.

Finalmente, en la cesión de la autoría del relato a los jóvenes -ahora portadores de la palabra- la relación intergeneracional se invierte; y quienes son tantas veces pensados como receptores para escuchar y aprender, ahora hablan y también enseñan. Es decir, que se produce un ida y vuelta que enriquece la actividad y potencia el trabajo de construir memoria social. La reciprocidad opera en el marco del proyecto.

Otra de las actividades son los ciclos denominados Teatro por la Identidad, ciclo que fue propuesto por la Agrupación Abuelas de Plaza de Mayo como espacio creativo a partir del tema de la apropiación de bebés durante la dictadura. El proyecto se lleva a cabo en la actualidad con producción propia y participación de autores e intérpretes locales.

A partir del año 2009, también desde el área de Derechos Humanos el Municipio aportó datos acerca de un CCD que no figuraba en los registros de la CONADEP: la Regional de Inteligencia de Buenos Aires (RIBA), utilizada como cárcel de paso de numerosos detenidos-desaparecidos de la zona oeste, ubicada en una propiedad de dos plantas en pleno centro de Morón (calle San Martín 700) ${ }^{25}$, actualmente se encuentra en curso el proceso de traspaso definitivo de la ex Regional al Estado local. Pero ya se realizan actividades en torno a esta temática y está abierta al público desde el 11 de noviembre de 2006.

Por otra parte, la concreción de talleres y jornadas de discusión han sido una de las tareas constantes desde la inauguración de la Casa de la Memoria y la Vida, actividades que han incorporado la participación de instituciones en general y educativas en particular ${ }^{26}$, las actividades son realizadas por docentes que dependen del Municipio.

La producción de eventos con el objetivo de promover la reflexión y la producción artística y documental en torno a la temática de recuperación y construcción de la memoria colectiva se lleva a cabo periódicamente a través de la presentación de libros, charlas, proyecciones, muestras (permanentes y temporarias), conciertos.

Desde el año 2000, la Casa de la Memoria y la Vida se convirtió en un espacio dedicado a recuperar y ejercitar la memoria, por lo que dio prioridad a la creación del Centro documental, allí funciona una biblioteca, hemeroteca, videoteca y archivos de otros soportes documentales. Este centro está vinculado a los derechos humanos, sociales y material histórico abierto a la consulta de la comunidad en general y en especial a los estudiantes. 
Las actividades de la Casa de la Memoria se desarrollan también en conexión con otras áreas del Municipio, y se articulan con programas, proyectos y trabajos de diversas entidades y organismos de Derechos Humanos, así como también con otras áreas gubernamentales provinciales y nacionales ${ }^{27}$

\section{A modo de conclusión: un avance acerca de los alcances y las limitaciones del proyecto Casa de la Memoria y La Vida.}

La necesidad de construir una memoria del pasado que nos signifique algo, que nos aventure hacia la reflexión. Como una huella intrínseca que mueve hacia delante, como una rugosidad que molesta en la linealidad de la historia contada con mayúscula. Como señala Rabotnikof "la distinción entre memoria colectiva, elaboración histórica y usos políticos del pasado resulta (aún hoy) teóricamente problemática. Con la idea de "usos políticos del pasado" me refiero a las particulares combinaciones entre memoria y olvido y a las formas diferentes de traer al presente esos fragmentos del pasado" (2005:22).

Creemos que dicha construcción se está llevando adelante en el Proyecto de la Casa de la Memoria y La Vida, en el Municipio de Morón, sin embargo, debemos a aventurarnos al planteo de la difícil pregunta acerca de sus alcances en general.

El presente trabajo ha intentado recuperar la importancia que el aparato político municipal depositó en la construcción de una política pública de la memoria, convirtiéndola en uno de los vectores más sobresalientes de su gestión, en un emplazamiento territorial al cual se lo ha investido y resignificado para dar como resultado la construcción de un Lugar de Memoria. Al decir de Tamburrini "a diferencia de un museo para la contemplación pasiva, la Casa de la Memoria y la Vida es desde hace ya una década punto de encuentro para el debate y el lanzamiento de nuevas ideas. Nos falta aún rellenar las páginas en blanco de nuestra historia reciente. Tenemos todavía una cita pendiente con los desaparecidos. La tarea urge, el tiempo se acaba. Mientras tanto, la casa espera paciente" (Morón 10 años después Apuntes de la Gestión de Gobierno 199-2009, pág. 242).

La memoria, en definitiva, es un acto del presente sobre un pasado. Como afirma Escolar "el mayor riesgo que corre la memoria es institucionalizarse y quedar encerrada en una interpretación oficial, clausurada, separada de la vida de los pueblos, de la historia que transcurre" (2009:10)

El espacio abierto por la concreción del Proyecto analizado posibilita el trabajo de esta construcción cotidiana y colectiva. Si pensamos en la reconfiguración del lugar, entendemos que este proceso logró, ampliar el marco de participación y reflexión sobre la memoria acerca de los hechos de la última dictadura convirtiéndose en un canal para visibilizar un proceso que había estado oculto e invisible en el pasado, a través de su posibilidad para hacer público lo que antes estaba anclado en el silencio.

\section{Notas}

1.Agradezco profundamente a Cora Escolar los comentarios reflexivos y aportes teóricoconceptuales que sirvieron para la concreción de este trabajo.

2.Como señala Estébanez (1988; 357-358) en el sistema intraurbano se analiza la forma o paisaje urbano atendiendo al entorno material dado por el emplazamiento y la situación, los componentes objetivos físicos: el plano, los usos del suelo, y la trama edificada. Estos componentes se analizan y estudian en sus múltiples combinaciones dando lugar a urbitopos: unidades homogéneas del paisaje urbano.

\section{El destacado es nuestro.}

4.Aquí conviene mencionar que "la mirada sobre las políticas públicas presenta, en una primera aproximación, dos aspectos fundamentales (...): la formulación de políticas (el diseño) tal como se constituye en objeto de las Ciencias Políticas y su implementación (la gestión burocrática) 
habitualmente analizada desde perspectivas más afines a las ciencias de la administración y organizaciones institucionales. Ambas instancias (...) constituyen momentos abstractos de un mismo proceso, que no resulta inteligible si la política pública en cuestión se observa desde una sola de estas perspectivas" (Escolar, Besse y Lourido; 1994:136). Sostenemos que "toda política pública es el producto del enfrentamiento y la negociación entre diferentes proyectos, los que a su vez se emergen de diferentes actores sociales. En tal sentido, si interpretamos a las políticas públicas como resultado de estas negociaciones sociales, podemos considerarlas como indicadores de la distribución del poder dentro del mismo estado como así también de la sociedad" (Escolar, Besse y Lourido; 1994: 137)

5.Los tres elementos principales del concepto de lugar implican: el locale (los emplazamientos en los cuales se constituyen las relaciones sociales tanto informales como institucionales); la localización (los efectos de los procesos sociales y económicos sobre los locales operando a escalas más amplias); y el sentido de lugar (la estructura del sentimiento local que da el emplazamiento). Entonces, "el lugar hace referencia a áreas discretas pero elásticas, en las que están localizados los emplazamientos para la construcción de las relaciones sociales y con las que los individuos pueden identificarse. Los itinerarios y proyectos de la vida cotidiana (...) proporcionan el pegamento práctico para el lugar en estos tres aspectos" (Agnew: 1993:14)

6.Por enclave territorial se entiende aquí la idea de que un espacio delimitado posee tanto una dimensión política o jurídico - política (en tanto referencia a las relaciones de poder), una dimensión cultural o simbólica, en tanto dimensión subjetiva y una dimensión económica (en tanto dimensión productiva del espacio). El territorio no es un mero sistema de objetos y de acciones en un sentido funcional, pues estos están siempre cargados de diversos significados que imprimen una veta simbólica en su constitución. Ver Haesbaert (2004)

7.Morón 10 años después, apuntes de la Gestión de Gobierno 1999-2009, pág. 27.
8.Ubicada en la Calle Blas Parera, límite entre las localidades de Castelar e Ituzaingó, Partido de Morón, provincia de Buenos Aires.

9. Rey de los hunos (c. 433-453), conocido en Occidente como 'El azote de Dios', Atila fue símbolo más terrible amenaza para el cristianismo: un rey que a diferencia de sus antecesores tenía esa clase de ambición desmedida que caracteriza a los gobernantes que han dejado una estela imborrable de crueldad y ferocidad guerrera en el corto tiempo que prácticamente tuvieron el poder del mundo en sus manos.

10.Claudio Tamburini, Guillermo Fernández, Daniel Rusomano y Carlos García, quienes lograron escapar el 24 de marzo de 1978, descolgándose desde una ventana del primer piso, desnudos y esposados. Sobre el relato de la fuga puede consultarse el libro escrito por uno de ellos, Tamburrini, Claudio. En sus agradecimientos el autor hace referencia explícita a cómo construyó el relato "gran parte del material presentado en esta novela ha sido recuperado del olvido durante las charlas con Guillermo Fernández, también protagonista de la historia" (2002). Esta novela fue base para la película "Crónica de una fuga" con dirección de Israel Adrián Caetano estrenada en el año 2006.

11.Los impulsores municipales de este proyecto llevaron adelante el lema "Crear vida donde existió muerte". Una vez inaugurado el Polideportivo Gorki Grana se colocó una placa conmemorativa en la entrada al predio donde se lee "Para que el Nunca Más sea realidad manteniendo la memoria de nuestro pueblo, los gremios, las fuerzas políticas, las Asociaciones de derechos humanos de Morón en homenaje a las Víctimas del Terrorismo de Estado. Día Universal de los Derechos Humanos, 10 de diciembre de 1986"

12. Este siniestro personaje del menemismo había sido hombre de José López Rega en el Ministerio de Bienestar Social, fachada legal de la Alianza Anticomunista Argentina, conocida como la Triple A. 
13. Entre las personas que participaron en la concreción del Proyecto Mansión seré podemos citar a: Nora Cortiñas (madre de Plaza de Mayo línea fundadora), Jaime Steimberg, Sara Ludmer de Steimberg (padres de Luis Steimberg, desaparecido), Antonela Di Vruno (directora de Derechos Humanos en Morón).

14.Entendemos por prácticas de marcación territorial, las diversas acciones y gestiones que se generaron y desplegaron en el ex Centro Clandestino de Detención con el fin de reconvertir el sitio. Es decir, diversas tácticas y estrategias implementadas con el fin de visibilizar socialmente, mediante la política municipal, el Lugar de memoria, una de ellas es la placa que aparece en el predio del Gorki Grana, como así también la placa recordatoria de las víctimas en la Plaza San Martín de Morón, ubicada en el centro de dicho Municipio.

15. Los lugares así marcados materializan la memoria a través de sus valores icónicos o lo que ellos promueven y generan; existen entonces lugares de valor de la memoria colectiva (Edensor: 1997), se convierten en lugares simbólicos porque invisten, porque poseen cierto status "para ser recordados" , status que puede ser alterado con el correr del tiempo, o por los avatares sociales, políticos y/o ideológicos. (Radley, 1990; Bustigorry, 2005). El status de los objetos y lugares que son susceptibles de recuerdo, conmemoración u homenaje es el resultado de una construcción y definición social, cultural y política.

16.El dispositivo es esa especie de madeja u ovillo, es un conjunto multilineal en donde las líneas de naturalezas diversas, de líneas que se acercan y se alejan, se chocan, se enmarañan permiten pensar en la fragilidad de lo universal y cristalizado, las totalizaciones y linealidades (Delleuze; 1988).

17."En toda sociedad, la producción del discurso está a la vez controlada, seleccionada y redistribuida por un cierto número de procedimientos que tiene por función conjurar los poderes y peligros, dominar el acontecimiento aleatorio y esquivar su pesada y terrible materialidad (...) se sabe que no se tienen derecho a decirlo todo, que no se puede hablar de todo en cualquier circunstancia, que cualquiera, en fin, no pude hablar de cualquier cosa" (Foucault; 2002, [1973] :14)

18. Más allá de lo propuesto por la Geografía Cognitiva acerca de los mapas mentales, vinculamos este concepto a la idea de que son las interpretaciones subjetivas en relación a cómo el espacio es vivido, representado y cómo es hablado-narrado lo que posibilita la emergencia de la apropiación de los lugares "nunca se percibe el medio objetivo en su totalidad [por que el sujeto] no dispone de toda la información para ello. Su imagen o mapa mental no es isomorfo con la realidad" (Estébanez: 1988:265). Estos sitios de memoria ingresan (y son ingresados por los sujetos) en un nuevo ámbito de relaciones sociales, culturales, políticas, educativas y recreativas.

19.Extraído de Morón 10 años después, apuntes de la Gestión de Gobierno 1999-2009, pág. 28.

20.Actualmente en curso se encuentra la Causa Seré, a cargo del Juez Daniel Rafecas, en la que el Municipio fue citado como testigo para aportar testimonio acerca del uso de la Mansión seré como CCD.

21.En el año 2009 se aprobó la construcción de un cerramiento vidriado y pasarelas internas para facilitar el recorrido de este sitio, que incluye además cartelería informativa y un sector de exposición. Al mismo tiempo se incorporará un laboratorio arqueológico y de conservación, junto con un depósito de materiales arqueológicos.

22. Extraído de Morón 10 anõs después, apuntes de la Gestión de Gobierno 1999, pág. 131

23. La Comisión Provincial por la Memoria es un organismo autónomo y autárquico respecto de los tres poderes del Estado, la integran reconocidos defensores de los Derechos Humanos, provenientes tanto de los organismos, como de distintas asociaciones sindicales, distintas iglesias, la universidad pública y otros ámbitos de la cultura. La integran el Premio Nóbel de 
la Paz Adolfo Pérez Esquivel, el ex Fiscal Hugo Cañón, la hermana Martha Pelloni, el obispo Aldo Etchegoyen, Laura Conte, Victor Mendibil, Emilce Moler, Susana Méndez, Mauricio Tenembaun, Carlos Sánchez Viamonte, Alejandro Mosquera, Fortunato Mallimaci, Roberto Tito Cossa, Luis Lima, Elizabeth Rivas, Elisa Carca, Verónica Piccone, Victor De Gennaro, Daniel Goldman y Mempo Giardinelli. La Comisión creó en el año 2003 el Comité Contra la Tortura, un programa que realiza tareas de monitoreo en los lugares de detención en la provincia, inspeccionando periódicamente cárceles, comisarías e institutos de menores. Anualmente, el Comité publica -desde el año 2004- un informe exhaustivo sobre violaciones a los derechos humanos en los lugares de detención y efectúa un análisis de las políticas penitenciarias, de seguridad y de niñez.

24. El Programa financia trabajos de investigación y producciones de los estudiantes relacionadas con el Golpe de Estado y sus consecuencias (libros, documentales, obras de teatro o exposiciones plásticas) y organiza la muestra de esa producción en un encuentro anual en la Ciudad de Chapadmalal. El soporte es también una elección: un video, un mural, una obra de teatro, una intervención urbana, una muestra fotográfica, un CD multimedia, una página Web, una revista, un libro, un programa de radio, etcétera.
25. Este lugar conformó junto con la Mansión Seré, la Comisaría de Castelar y el Chalet del Hospital Posadas un corredor de detenciones clandestinas, torturas y desapariciones.

26. El enfoque de dichas prácticas está orientada a la discusión de los derechos humanos en el análisis de la historia reciente de nuestro país (desde finales del siglo XIX hasta nuestros día), sobre el eje de los modelos de producción, inclusión/exclusión y participación ciudadana, tomando como punto de quiebre e inflexión la última dictadura militar con una escala territorial que abarca la zona oeste del conurbano bonaerense.

27.Entre ellos puede mencionarse: Asociación Seré por la Memoria y la Vida, Madres de Plaza de Mayo línea fundadora, abuelas de Plaza de Mayo, H.I.J.O.S. Zona Oeste, Memoria Abierta, Comisión provincial por la Memoria, Familiares de Detenidos y Desaparecidos por cuestiones Políticas, Ma.Fa. Vi.,¿Quiénes Somos?, Raíz Natal, INADI, Teatro por la Identidad, GLOBA., Secretaría de Derechos Humanos de la Nación, la Secretaría de Derechos Humanos de la Provincia de Buenos Aires y el Área de Conservación de Patrimonio del Gobierno de la Ciudad Autónoma de Buenos Aires.
ACHUGAR, Hugo (2003): "El lugar de la memoria, a propósito de monumentos (motivos y paréntesis)"; en: LANGLAND, Victoria y E. Jelin (comps.), 2003: Monumentos y marcas territoriales, Madrid, Siglo XXI/ SSRC.

AGNEW, John (1993): "Representing space. Space, scale and culture in social science" en: Duncan, J. y L. David (eds): Place/culture/representation, Routeledge, Londres.

BESSE, Juan (2005): "Memoria urbana y lugares patrimoniales. Elementos teóricos para el abordaje de las marcas territoriales asociadas a acontecimientos políticos" en: Taller
Internacional Desplazamientos, contactos, lugares. La experiencia de la movilidad y la construcción de 'otras geografías', IG, FFyL, UBA, Buenos Aires, mayo 2005.

BUSTIGORRY, Florencia (2005): "Los lugares de la memoria. Los significantes urbanos que dan cuenta de la última dictadura militar en la Argentina". En; Terceras Jornadas de Investigación en Antropología Social, FFYL, UBA.

CALETTI, Sergio: "La crítica política y los descentramientos de la memoria. Apuntes en torno a la valoración de los años '70" En: Pensamiento de los confines, No 1, 2 do. Semestre. 
CERTEAU de, Michel (1974): "Conclusión: De los espacios y las prácticas" en: La Cultura en Plural, Ed. Nueva Visión, Buenos Aires.

CARTER, Harold (1983): El estudio de la geografía urbana, Instituto de Estudios de Administración local, Madrid.

DELLEUZE, Pilles (1988): "¿Qué es un dispositivo?, en Michel Foucault, filósofo, Barcelona.

DIAZ, Diego (2002): "El mapa de la memoria". En: Revista Puentes de La memoria No 7, (pág. 34-39).

En <www.memoriaenelmercosur.edu.ar. $>$

ENTRIKIN, J. Nicholas (1988): "Lugar, región y modernidad" en:

ESCOLAR, Cora (2009) "Memoria y vida. Reflexiones epistemológicas acerca del discurso institucionalizado de la memoria" En: ACCIONES, Investigaciones Sociales, Universidad de Zaragoza, ISSN: 1132-19X.

ESCOLAR, Cora, J. Besse y C. Lourido (1994): "Redes para 'pescar' lo real (un abordaje teórico-metodológico)" en: Revista Realidad Económica, No 124, IADE, Buenos Aires.

ESCOLAR, C y C. Palacios (2010): "La producción del espacio urbano y la dimensión espacial de las prácticas institucionales. El caso del Espacio para La Memoria y Para la Promoción y defensa de los Derechos Humanos (Ex ESMA) en: XI Coloquio internacional de Geocrítica, Buenos Aires. URL: www.eventosfilo.uba.ar/geocritica

ESTÉBANEZ, José (1988): "Capítulo IV: Los espacios Urbanos" en: Rafael Puyol, José Estébanez y Ricardo Méndez: Geografía Humana, Ed. Cátedra, Madrid.

FOUCAULT, Michel (2002) [1973]: El Orden del discurso, Tusquest Ediciones, Barcelona.

HARVEY, David (1992): Condiçaõ Pós-Moderna, Edições Loyola, São Paulo.

HAESBAERT, Rogério (2004): "De la desterritorialización a la Multiterritorialidad" en: El mito de la desterritorialización. Del "fin de los territorios" a la multiterritorialidad, Río de Janeiro, Bertrand Brasil Ltda.

HUYSSEN, Andreas (2002): En busca del futuro perdido. Cultura y memoria en tiempos de globalización. FCE, México.

JELIN, Elizabeth (2002): Los trabajos de la memoria. Madrid, Siglo XXI/SSRC.

KAËS, René (1991): "Rupturas catastróficas y trabajo de memoria. Notas para una investigación". En: PUGET, Janine y R. Kaës Violencia de estado y psicoanálisis, Buenos Aires, CEAL.

LE GOFF, Jacques (1977): "El orden de la memoria". En: El orden de la memoria. El tiempo como imaginario. Barcelona, Paidós Básica, 1991.

LORENZ, Chris ( $\mathrm{s} / \mathrm{r}$ ) "¿La historia como trauma? Los debates de los historiadores alemanes sobre el Tercer Reich" (Mimeo).

MESSINA, Luciana (2009): "La construcción de un lugar de memoria: el caso del es centro clandestino de detención, 'Olimpo' ", en Cuadernos del instituto Nacional de Antropología y pensamiento Latinoamericano, Buenos Aires, No 22.

NORA, Pierre (1998): "La aventura de Les Linux de mémoire" En: Josefina Cuesta Bustillo (ed.); Memoria e Historia, Marcial Pons, Madrid. (Pág. 17-34)

ORTEGA VÁRCARCEL, José (2000): "Tercera Parte: objetos y prácticas de la Geografía" en: Los horizontes de la Geografía, Ariel, Barcelona.

PORTILLO, Álvaro (1991): "Sentido económico de la urbanización capitalista" en: Ciudad y Conflicto. Un análisis de la urbanización capitalista, Ed. Compañeros, Montevideo, Uruguay.

RABOTNIKOF, Nora (2005): Memoria y política: el juego de I tiempo en las transiciones" en: Ponencia presentada en el Seminario de Estudios Avanzados Instituto de investigaciones Sociales, UNAM/ Fundación Friedrich Ebert: "Izquierda, sociedad 
y democracia. Hay un futuro democrático para América Latina?.

RAGGIO, Sandra (2006): "Los jóvenes y la memoria". Programa Jóvenes y memoria. URL: www. comisionporlamemoria.org/jovenesymemoria/

SONDERÉGUER, María (2000): "Los relatos del pasado reciente en argentina: una política de la memoria". En: Congreso LASA 2000, DEMDerechos humanos y democracia en Argentina: un programa interdisciplinario. URL: www. prodiversitas.bioetica.org/notas.htm-

TAMBURRINI, Claudio (2002): Pase Libre. La Fuga de la Mansión Seré, Ediciones Continente, Buenos Aires.

TODOROV, Tzvetan (1995) Los abusos de la memoria. Barcelona, Paidós Asterisco, 2000.
WERLEN, Benno (1988): Sociey, action and space. An alternative human geography, Routeledge, Londres- New York.

WILLIAMS, Raymond [1977](1980): Marxismo y Literatura, Editorial Península, Barcelona, España.

Materiales de apoyo:

Morón diez años después. Apuntes de la Gestión de Gobierno 1999-2009. Disponible en: <http://www.pagina12.com.ar/2000/00-07-02>

<http://elgrafico.com.ar/popu imprimir.php?tbl> <http://www.eldiariodemoron.com.ar/pdf/ generar $\mathrm{pdf}>$

$<$ http://polticaargentina.suite101.net/article. cfm/la-casa-de-la-memoria-y-de-la-vida-cumpleanos $>$

< ht t p://ww w.redeco.com.ar/ anteriores2006/.../141106.htm> 